\title{
Combined endoscopic and computed tomography guided trans-nasal embolisation of intramuscular hemangioma of the medial rectus muscle: a rare case
}

\author{
Sibasankar Dalai ${ }^{1 *}$, Surendra Lele ${ }^{2}$, Maya Gantayet ${ }^{3}$, Aravind V. Datla ${ }^{4}$
}

\author{
${ }^{1}$ Department of Interventional Neuroradiology, Medicover Hospitals Visakhapatnam, Andhra Pradesh, India \\ ${ }^{2}$ Department of Otorhinolaryngology, Seven Hills Hospital Visakhapatnam, Andhra Pradesh, India \\ ${ }^{3}$ Department of Neurology, Ashwini Hospital Cuttack, Odisha, India \\ ${ }^{4}$ Department of Internal Medicine, Medicover Hospitals Visakhapatnam, Andhra Pradesh, India
}

Received: 26 January 2022

Accepted: 10 February 2022

\section{*Correspondence:}

Dr. Sibasankar Dalai,

E-mail: inrresearch2021@gmail.com

Copyright: $(\odot$ the author(s), publisher and licensee Medip Academy. This is an open-access article distributed under the terms of the Creative Commons Attribution Non-Commercial License, which permits unrestricted non-commercial use, distribution, and reproduction in any medium, provided the original work is properly cited.

\begin{abstract}
Hemangiomas are benign vascular malformations. Intramuscular hemangiomas (IMH) of the extraocular muscles are exceedingly rare. So far, only eight cases have been previously reported in the medical literature till date. We report a rare case of an intramuscular hemangioma of the medial rectus muscle presenting severe pain in the right eye and redness in the right sclera. We administered analgesics and steroids for six weeks, with no pain relief. Right ethmoidal dissection was done, and a window was made over the lamina papyracea, and a needle was placed directly into the mass under combined endoscopy and computed tomography (CT)-scan guidance. The mass was embolised with $33 \%$ glue and lipiodol. The patient recovered from the pain, and complete vision was restored. Eye discolouration got wholly cured within two weeks.
\end{abstract}

Keywords: IMH, Medial rectus, Lamina papyracea, Endoscopic guidance, CT guided, Trans-nasal embolization, Nbutyl cyanoacrylate, Lipiodol

\section{INTRODUCTION}

Hemangiomas are benign vascular malformations. They may occur anywhere in the body and affect $0.3-0.7 \%$ of the population. ${ }^{1}$ Hemangioma is the most common benign neoplasms of orbit reported in adults. ${ }^{2}$ They are primarily located lateral to the optic nerve, within the muscle cone. IMH, which affect the skeletal muscles, are rare, accounting for $<1 \%$ of all hemangiomas. IMHs of the extraocular muscles are exceedingly rare. So far, only eight cases have been previously reported in the medical literature till date. ${ }^{3}$ Surgical interventions are generally reserved for symptomatic patients. We report a rare case of an IMH of the medial rectus muscle. We opted for an interdisciplinary approach to annihilate the lesion successfully.

\section{CASE REPORT}

A 48-year-old male, otherwise healthy, presented with severe pain in the right orbital region and diplopia. Upon ophthalmological examination, he had severe redness in the right sclera (Figure 1). The vision in both eyes was $6 / 6$. The pupils were normal in size, bilaterally symmetrical and had normal direct and indirect light reflexes. There was non-axial proptosis in the right eye with restriction of ocular movements, especially abduction. Tono-Pen tonometry was normal. Visual fields were regular. Slit-lamp examination was normal, except for the scleral haemorrhage. Fundoscopy revealed no further abnormalities. CT of the orbits and brain was done. The CT revealed an IMH in the retro-orbital space within the medial rectus muscle (Figure 2 and 3). A 
cerebral digital subtraction angiogram ruled out other arteriovenous malformation.

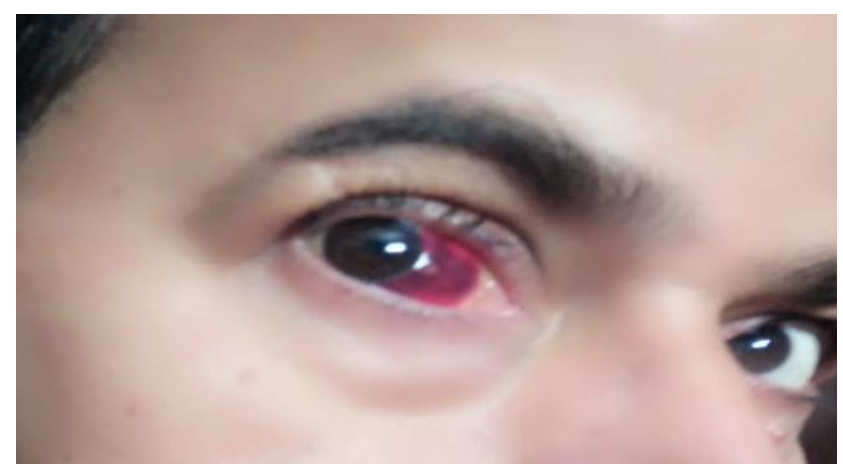

Figure 1: Subconjunctival hemorrhage in the medial side of the right eye.

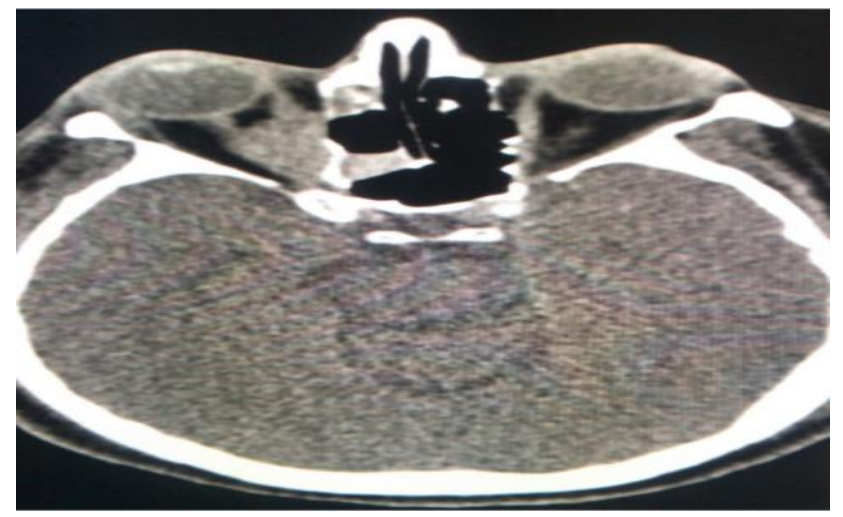

Figure 2: CT axial view showing increased bulk of the medial rectus muscle (IMH of the medial rectus).

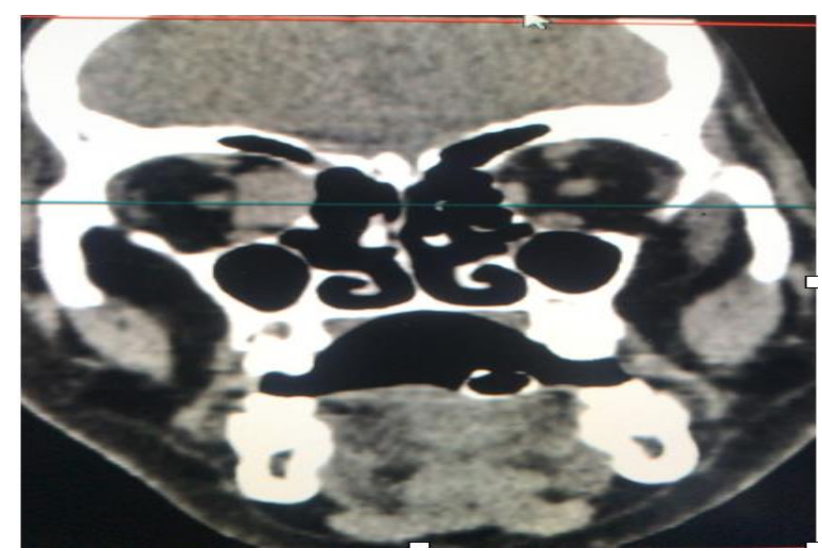

Figure 3: CT coronal view showing increased bulk of the medial rectus muscle (IMH of the medial rectus).

The patient initially received analgesics and steroids for six weeks. However, the patient did not respond to this regimen.

A team consisting of interventional neurologists, ENT surgeons, and ophthalmologists discussed possible treatment options.
The patient had a deviated nasal septum to the right. A limited septoplasty was done to gain access to the right middle meatus. A right ethmoidectomy was done to expose the right lamina papyracea. A one-centimetre window was created in the lamina papyracea adjacent to the area of hemangioma to gain access to the orbital lesion trans-nasally. Periorbita was kept intact. Nasal packing was done with merocele pieces in the middle meatus, and the right nasal cavity packs were removed after three days. The patient was taken to the Cath lab to take control of any possible bleeder during pack removal. The patient was then moved to a CT scan unit.

The procedure was done under general anaesthesia in the CT scan suite. With the help of a nasal endoscopic camera and a CT scan, a 22-gauge LP needle with J shaped tip was placed through the lamina papyracea window such that the tip of the needle was at the centre of the tumour. The position of the needle was confirmed with CT imaging. Upon the appearance of frank blood, aspiration was performed, and the aspirate underwent histopathological examination. The tumour was then embolised with $2 \mathrm{cc}$ of $33 \%$ glue-lipiodol mixture. CT scan showed an even distribution of glue (n-butyl cyanoacrylate) and lipiodol (iodized oil) in the tumour without extravasation into the retro-orbital space (Figure 4 and 5). After completing the procedure, the patient was shifted to ICU for close observation for one day, followed by observation in the ward.

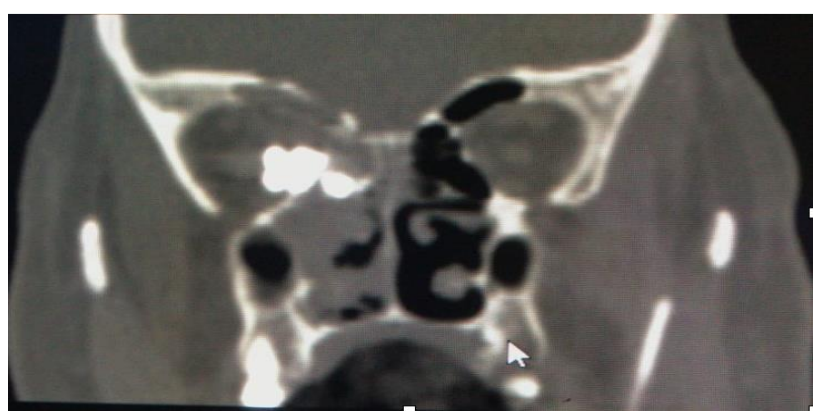

Figure 4: Post-procedural CT coronal view showing embolised hemangioma without any extravasation of the glue.

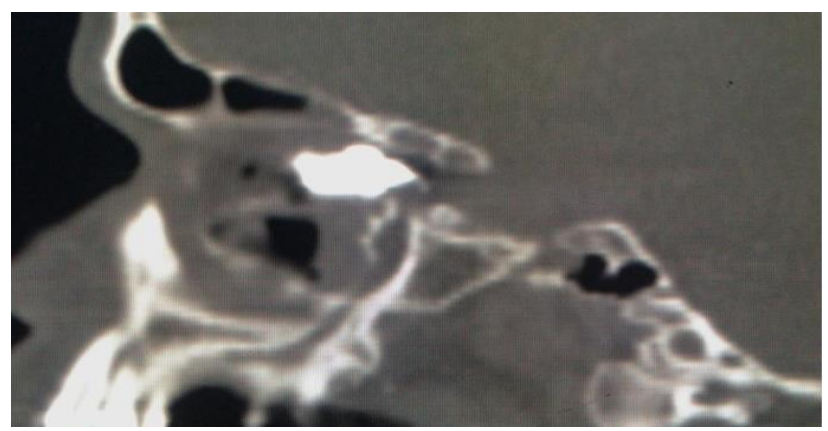

Figure 5: Post-procedural CT sagittal view showing embolised hemangioma without any extravasation of the glue. 
The pain subsided completely. Post-procedure vision blurring returned to normal in the next three days. Diplopia got rectified during hospitalisation. The redness of the eye was completely cured within two weeks of discharge (Figure 6).

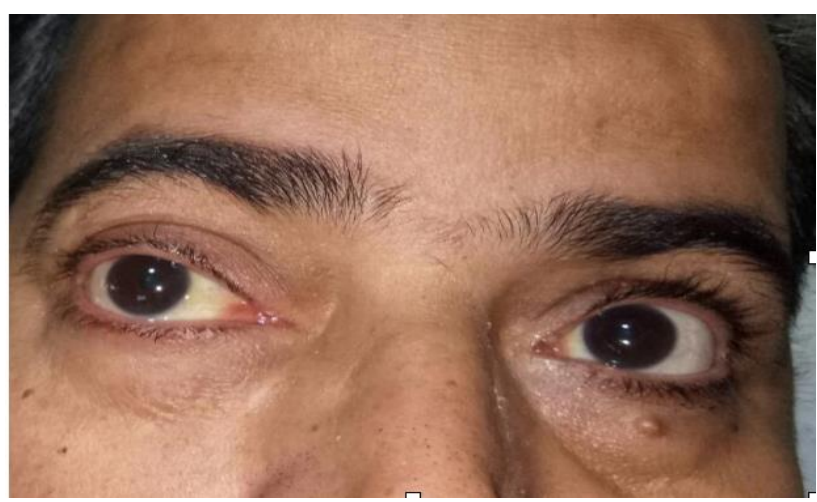

Figure 6: Complete resolution of the subconjunctival hemorrhage.

\section{DISCUSSION}

Hemangiomas are the most common type of orbital lesion reported in adults. ${ }^{2}$ They may occur at any location within the orbit but are most commonly reported at the middle third of the orbit (within the intraconal space) with a preference for the left orbit. ${ }^{4}$ These are usually solitary, encapsulated venous malformations and mostly present with symptoms like painless proptosis, pain, lid swelling, lump, obstructed vision and diplopia. Most of these tumefactions are unilateral. Bilateral cases have been rarely reported.

Hemangiomas generally remain asymptomatic until adulthood and rarely presents symptoms in children. The condition is more prevalent in women, and recent reports suggest that female sex hormones may play a role in clinical presentation. ${ }^{5}$

Ultrasound, CT, or MRI typically establishes a diagnosis of IMH. However, ultrasound is inferior to CT and MRI regarding the location of lesion and relationship with surrounding structures. ${ }^{6}$ Various treatment methods are available for treating hemangiomas, ranging from surgical interventions to non-surgical management. Systemic steroids can decrease the bulk of the tumour, but IMHs are insensitive to systemic corticosteroids because of encapsulation and the presence of cavernous elements which are resistant to corticosteroids. ${ }^{7}$ The use of intralesional steroid injection might lead to significant retrobulbar hemorrhage.

Although open surgical excision is the treatment of choice, recurrence rates range from 9 to $28 \%$ even after wide resection of a cuff of normal muscle around the tumour. ${ }^{3}$ This approach may be too radical in the extraocular region, leaving the patient with a significant irreversible ocular motility disorder.
In recent years, using endoscopic management of intraconal cavernous hemangiomas became popular. Lenzi et al found the endoscopic management of intraconal cavernous hemangiomas to be feasible and safe. $^{8}$

In this report, we present a case of IMH of the medial rectus muscle, which is an exceedingly rare occurrence. The first case of an intramuscular hemangioma affecting the extraocular muscles was reported by Christensen et al. ${ }^{9}$ Since then, a total of eight cases have been published in the literature..$^{3,9-14}$ The ages ranged from 3 to 63 years, affecting both genders. Due to the rarity of this presentation, there is no standardised treatment protocol. A plethora of medications and surgical techniques have been used, yielding variable results. In our case, the scleral haemorrhage was significantly affecting the vision; the pain was not responding to medical management. Hence, we took an unusual approach to completely treat the tumour by trans-nasal direct embolisation with glue and lipiodol.

Vascular embolization is a minimally invasive treatment. Cyanoacrylate liquid glues are preferred for embolization owing to their low viscosity, rapid polymerization rate, good penetration ability and low tissue toxicity. ${ }^{15}$ The glue-lipiodol mixture being radiopaque allows the operator to assess the direction of glue travel when used with a CT. Nasal endoscopy significantly aided with the needle placement. Fluoroscopic guidance would not delineate the complex anatomical relation between various structures or the direction of glue travel at the maxillary facial region.

\section{CONCLUSION}

Though hemangiomas are the most common type of orbital lesions, IMHs are exceedingly rare. CT or MRI are typically adequate to establish a diagnosis when associated with typical symptoms. Guided embolization appears to produce more favourable results when compared to an open surgical procedure in our opinion.

\section{Funding: No funding sources \\ Conflict of interest: None declared \\ Ethical approval: Not required}

\section{REFERENCES}

1. Moriarity JL, Wetzel M, Clatterbuck RE. The natural history of cavernous malformations: a prospective study of 68 patients. Neurosurgery. 1999;44(6):116673.

2. Calandriello L, Grimaldi G, Petrone G. Cavernous venous malformation (cavernous hemangioma) of the orbit: Current concepts and a review of the literature. Surv Ophthalmol. 2017;62(4):393-403.

3. Gade PS, Naik H, Bhople L, Velho V. Intramuscular hemangioma of the medial rectus as a rare cause of 
extraocular muscle enlargement: Report and review of literature. Neurol India 2019;67:601-4.

4. McNab AA, Selva D, Hardy TG, O’Donnell B. The Anatomical Location and Laterality of Orbital Cavernous Haemangiomas. Orbit. 2014;33: 359-62.

5. Jayaram A, Lissner GS, Cohen LM, Karagianis AG. Potential correlation between menopausal status and the clinical course of orbital cavernous hemangiomas. Ophthalmic Plast Reconstr Surg. 2015;31(3):187-90.

6. Tian YM, Xiao LH, Gao XW. Adhesion of cavernous hemangioma in the orbit revealed by CT and MRI: analysis of 97 cases. Int J Ophthalmol. 2015;4(2):195-8.

7. Allen PW, Enzinger FM. Hemangioma of skeletal muscle. An analysis of 89 cases. Cancer. 1972;29(1):8-22.

8. Lenzi R, Bleier BS, Felisati G, Muscatello L. Purely endoscopic trans-nasal management of orbital intraconal cavernous haemangiomas: a systematic review of the literature. Eur Arch Otorhinolaryngol. 2016;273(9):2319-22.

9. Christensen SR, Børgesen SE, Heegaard S, Prause JU. Orbital intramuscular haemangioma. Acta Ophthalmol Scand. 2002;80:336-9.

10. Kiratli H, Bilgiç S, Cağlar M, Söylemezoğlu F. Intramuscular hemangiomas of extraocular muscles. Ophthalmology 2003;110:564-8.
11. Kim SH, Shin HH, Rho BK, Lee ES, Baek SH. A case of intramuscular hemangioma presenting with large-angle hypertropia. Korean J Ophthalmol. 2006;20:195-8.

12. Lee BJ, Schoenfield L, Perry JD. Orbital intramuscular hemangioma enlarging during pregnancy. Ophthalmic Plast Reconstr Surg. 2009;25:491-3.

13. Charles NC, Belliappa S, Patel P. Intramuscular hemangioma of the inferior oblique: A rare cause of extraocular muscle enlargement. JAMA Ophthalmol. 2014;132:122-4.

14. Mehta A, Butola S, Naik M, Abrol S, Kumari A. Intramuscular cavernous hemangioma of medial rectus muscle in paediatric age group. Case Rep Ophthalmol Med. 2017;2017:1076404.

15. Li YJ, Barthès-Biesel D, Salsac AV. Polymerization kinetics of n-butyl cyanoacrylate glues used for vascular embolization. J mechanical behavior biomed materials. 2017;69:307-17.

Cite this article as: Dalai S, Lele S, Gantayet M, Datla AV. Combined endoscopic and computed tomography guided trans-nasal embolisation of intramuscular hemangioma of the medial rectus muscle: a rare case. Int J Otorhinolaryngol Head Neck Surg 2022;8:276-9. 